\title{
GINÁSTICA em rede, possibilidades PARA TODOS
}

\author{
Eliana de Toledo ${ }^{1}$ \\ Laurita Marconi Schiavon ${ }^{1}$ \\ Eliana Ayoub ${ }^{1}$ \\ Kizzy Fernandes Antualpa ${ }^{2}$ \\ Daniela Bento-Soares ${ }^{1}$ \\ Letícia Bartholomeu de Queiroz Lima ${ }^{1}$
}

Desde 2012, o Fórum Internacional de Ginástica para Todos (FIGPT) estabelece parceria com a Revista Conexões, por meio da publicação de edições temáticas de Ginástica, com produções científicas de destaque de pesquisadores que têm participado deste evento. Esta parceria se soma a outras que vem sendo realizadas desde a primeira edição do Fórum (em 2001), especialmente a que o consolida, entre a Faculdade de Educação Física da Unicamp e o Serviço Social do Comércio (Sesc), com o apoio da International Sport and Culture Association (Isca). Neste ano, a Faculdade de Ciências Aplicadas da Unicamp, por meio de seu curso de Ciências do Esporte, constitui-se também como parceira na realização do evento, tendo-o apoiado desde 2012.

A IX edição do Fórum Internacional de Ginástica para Todos de 2018 aborda o tema "Ginástica em rede, possibilidades para todos". A Ginástica para Todos (GPT) possibilita a prática da ginástica de forma integrativa, prazerosa e colaborativa, para todos os interessados, independentemente da faixa etária, gênero, etnia, classe social ou nível de performance. Tem como diferencial as próprias estratégias pedagógicas que vêm sendo produzidas por pesquisadores e instituições que a fomentam, almejando, sobretudo, a valorização da formação humana e a criação de vínculos. Assim, por meio da vivência da GPT, esses vínculos se ampliam e se fortalecem criando redes entre os praticantes e as instituições, que se apoiam e se comprometem na difusão de sua prática, e também colaborações institucionais, dentre outras.

Nesta edição do FIGPT, a Unicamp celebrou os 25 anos do Grupo de Pesquisa em Ginástica (FEF - Unicamp), dos quais aproximadamente 20 incluíram este grande projeto que é o Fórum. É com grande satisfação que constatamos, a cada edição, o crescimento e a qualificação das pesquisas relacionadas à área, assim como, da prática da Ginástica para

\footnotetext{
${ }^{1}$ Universidade Estadual de Campinas.

${ }^{2}$ Faculdades Integradas Metropolitanas de Campinas.

Contato: eliana.toledo@fca.unicamp.br
} 
Todos nos vários segmentos da sociedade, respaldados e fortalecidos por essa produção, que advém das três unidades da Unicamp parceiras neste evento: Faculdade de Ciências Aplicadas (FCA), Faculdade de Educação Física (FEF) e a Faculdade de Educação (FE).

O Sesc reconhece a importância deste evento pois, a partir dele, a GPT vem sendo difundida e continua em expansão nas suas diversas unidades, por meio da realização de festivais, capacitações e cursos permanentes. Também a parceria com instituições nacionais e internacionais, que acreditam na GPT como uma prática educativa, acessível, prazerosa e integrativa, renova-se a cada edição.

Esse crescimento constante se expressa no maior número de trabalhos científicos já submetidos e aprovados (121), produções de pesquisadores(as) e profissionais de todas as regiões brasileiras, assim como de outros países (Argentina, País de Gales, Portugal, República Tcheca e Suécia). O mesmo pode ser identificado na quantidade expressiva de grupos brasileiros e latino americanos de GPT, inscritos nos quatro festivais (cerca de 70 instituições e 90 coreografias). Essa enorme festa da Ginástica ficou ainda mais encantadora nesse ano, devido à presença também de grupos estrangeiros do Chile, da Grécia, da Dinamarca, do México e da República Tcheca se apresentando nos festivais.

Cabe ressaltar a presença do Comitê Técnico de GPT da Federação Internacional de Ginástica (FIG), com membros dos seguintes países: Brasil, Dinamarca, Eslováquia, Japão, Portugal, Suécia e Suíça. Esta presença se traduz como mais um reconhecimento acerca da importância deste evento para a área, e amplia as oportunidades de troca de conhecimento, em nível nacional e internacional, no campo da pesquisa, da extensão e do ensino (formal e nãoformal).

Nesse dossiê temático da Revista Conexões, trazemos cinco artigos de autores/as que apresentaram seus trabalhos no IX Fórum Internacional de Ginástica para Todos, realizado entre os dias 18 e 21 de outubro em Campinas/SP, e que foram selecionados por pareceristas ad hoc doutores da área, por meio de sistema duplo cego, em consonância com as normativas da revista.

Os artigos relativos à Ginástica para Todos que estão sendo aqui publicados abordam investigações em diferentes âmbitos, que vão desde estudos a respeito de grupos universitários de GPT, passando por reflexões sobre essa prática corporal na Educação Física escolar, assim como acerca da velhice e da divulgação científica.

No que se concerne às pesquisas relacionadas a grupos universitários, temos dois artigos: "A constituição e o processo coletivo de criação do Grupo Ginástico Unicamp pelas vozes de seus coordenadores", de Giovanna Regina Sarôa e Eliana Ayoub; e "Desmitificando a cultura cerratense por meio da Ginástica para Todos: um estudo de caso do Grupo de Ginástica Cignus", de Michelle Ferreira de Oliveira, Thiago Camargo Iwamoto, Lidia Acyole de Souza Oliveira e Eliana de Toledo. 
Em relação à ginástica no contexto da Educação Física escolar, está sendo publicado o seguinte artigo: “A Ginástica para Todos nas aulas de educação física: um estudo de caso", de Thyago Thacyano de Souza dos Santos, Juliana Nogueira Pontes Nobre, Claudia Mara Niquini e Priscila Lopes.

Encontramos, ainda, um artigo sobre idosos, intitulado "Influências da prática da Ginástica para Todos para a saúde na velhice: percepções dos praticantes”, de Natália Lopes Moreno e Mariana Harumi Cruz Tsukamoto.

E trazemos, igualmente, uma pesquisa que se refere à temática da difusão do conhecimento científico, cujo título é "A divulgação científica no Fórum Internacional de Ginástica para Todos", de Kássia Mitally da Costa Carvalho, Carla Thais Souza, Camila Sanchez Milani e Fernanda Raffi Menegaldo.

Gostaríamos, finalmente, de ressaltar que, nesses tempos em que circulam concepções que pretendem silenciar a democracia e a diversidade, a Ginástica para Todos torna-se ainda mais necessária e potente como possibilidade de continuarmos experimentando e produzindo coletivamente conhecimentos em rede, para todos/as e com todos/as.

Convidamos os/leitores/as para conhecer as investigações publicadas neste número, com o desejo de que encontrem significativas reflexões acerca da Ginástica para Todos e, de modo mais geral, possam ampliar seus conhecimentos a respeito das Ciências do Esporte e áreas correlatas, cuja divulgação é a missão da revista Conexões.

Saudações Ginásticas!

Dossiê "Ginástica para Todos" 